House of Commons International Development Committee (2004) Migration and Development: How to Make Migration Work for Poverty Reduction. Sixth Report of Session 2003-2004. Volume 1. Report Together With Formal Minutes. TSO.

Jenkins, R., Kydd, R., Mullen, P., et al (2010) International migration of doctors, and its impact on availability of psychiatrists in low income countries. PLOS One, 5(2), e9049. doi: http://dx.plos. org/10.1371/journal.pone.0009049.

Kirigia, J., Akpa Gbary, L. M., Nyoni, J., et al (2006) The cost of health professionals brain drain in Kenya. BMC Health Services Research, 6, 89.

Mackey, T. K. \& Liang, B. A. (2013) Restructuring brain drain: strengthening governance and financing for health worke migration. Global Health Action, 6, 1-7.
Mensah, K., Mackintosh, M. \& Henry, L. (2005) The 'Skills Drain' of Health Professionals from the Developing World: A Framework for Policy Formulation. MEDACT.

World Health Organization (2006) Health workers: a global profile. In The World Health Report 2006 - Working Together For Health. WHO. Available at http://www.who.int/whr/2006/whr06 en.pdf (accessed June 2016).

World Health Organization (2010) WHO Global Code of Practice on the International Recruitment of Health Personnel. WHO. Available at http://apps.who.int/gb/ebwha/pdf files/WHA63/A63 R16-en.pdf (accessed June 2016).

THEMATIC PAPER

${ }^{1}$ Professor and Dean, School of Nursing and Midwifery, Aga Khan University, East Africa, Khan Univerity, East Africa, email Sharon.brownie@aku. edu; Adjunct Professor School of Medicine, Griffith University, Australia; Research Associate and Member of the Oxford PRAXIS Forum, Green Templeton College, Oxford University, UK

${ }^{2}$ Quality Improvement Manager, Mathari National Teaching and Referral Hospital, Nairobi, Kenya

\title{
Health professionals in Kenya: strategies to expand reach and reduce brain drain of psychiatric nurses and psychiatrists
}

\author{
Sharon Brownie ${ }^{1}$ and Elizabeth Oywer ${ }^{2}$
}

This paper highlights the extent of the brain drain in relation to human resources for health (HRH) that is currently challenging Kenya, and suggests strategies that have the potential to change current working environments and improve HRH retention rates. Governments in partnership with health professional bodies and regulators could improve the working conditions for psychiatrists and mental health nurses: by promoting career choices in mental health; by providing accessible professional development opportunities; and by easing workload pressures by expanding service reach through thoughtfully planned and delivered task-shifting to primary care. While these strategies have the potential to make a significant difference, the evidence suggests a brain drain will continue as long as working conditions remain sub-optimal and global HRH shortages persist.

Much has been written about the highly complex and seemingly insurmountable issue of the brain drain of health professionals - the outward flow of skilled health professionals and the academics who teach them. The situation is particularly acute for mental health services in Kenya, where the numbers of specialist psychiatrists and mental health nurses fall well beneath the population ratios recommended by the World Health Organization (WHO). Much has also been written about current global shortages in human resources for health $(\mathrm{HRH})$, resulting from factors such as the higher pay and better working conditions in higher-income countries, although it should be noted that accurate HRH mental health data are difficult to source and verify.

Brain drain is a long-standing issue in Kenya. A search for contributing factors has been increasingly sought over the past two to three decades (Yonga et al, 2012; Odhiambo, 2013). Kenya has invested heavily in increasing its $\mathrm{HRH}$ but ratios still remain below the minimum levels recommended by the WHO (Oywer, 2011). It is difficult to source reliable and comparable data, but there is sufficient information available to confirm that Kenya remains on the list of countries identified by the WHO as having critical shortages in $\mathrm{HRH}$, with recently reported ratios of just 23 doctors, nurses and midwives per 100000 population (Otieno, 2016). Kenya is also challenged by the poor distribution of these resources across the country; there is a 13-fold difference between the highest- and lowest-resourced county.

Reportedly, one in every five nurses trained in Kenya applies to emigrate (Otieno, 2016). Figures for doctors are equally concerning, with a reported $30-40 \%$ of the 600 medical graduates leaving on completion of their internship, every year (Muraguri, 2015). Kenya also suffers a critical shortage of mental health nurses. Of the few that exist, the number of new graduates is not keeping pace with the numbers lost to the brain drain or retirement (Oywer, 2011).

The financial impact of the brain drain is substantial; in 2006 it was estimated that the total cost of educating each medical doctor, from primary school through medical college, was US\$65997. An estimated lost return on investment of approximately US $\$ 517931$ was incurred for every doctor who then emigrated. The total cost of educating a nurse from primary school to nursing graduation was estimated to be US $\$ 43180$, with an equivalent loss on investment to migration of US $\$ 338868$ (Kirigia et al, 2006). In response to these figures, Kenya scaled up the production of HRH. Consequently, there has been a reduction in the brain 
drain of Kenya's nursing workforce, according to data from the Nursing Council of Kenya (see Table 1). Despite these gains, recent reports paint an alarming picture of severe nursing shortages in some counties and significant concerns about the impact of overwork on the quality of healthcare (Otieno, 2016).

\section{The mental health workforce}

The situation pertaining to the mental health workforce appears to be even more worrying. Jenkins et al (2010) reported that there were few specialist psychiatrists, perhaps no more than 75 to support a population of around 40 million in 2010. Up to 28 of these work in private practice and 21 within university settings. Recruitment into mental health nursing remains low, despite efforts made by the Nursing Council of Kenya (Oywer, 2011). With the aim of increasing recruitment, in 2012 the Nursing Council, together with the Kenya Medical Training College, introduced a basic diploma in mental health nursing, and now two schools of nursing offer the course; the first classes have graduated. Despite these measures, the new nurses may not reach regions with the most critical need.

As highlighted above, Kenya's health sector is challenged by an inequitable distribution of nursing resources. The 2012 Kenya Nursing Workforce Report highlights the fact that approximately $68 \%$ of the nursing workforce is employed in a few hospitals that comprise just $8 \%$ of all health facilities. In contrast, only $20 \%$ of nurses work in community clinics and dispensaries, yet these facilities make up $72 \%$ of the country's health facilities (Kenya Ministry of Health \& Nursing Council of Kenya, 2012). Given the burden of mental health issues in the community, this uneven pattern results in an even greater strain upon an already underresourced system.

\section{Contributing factors}

Factors contributing to the brain drain are complex and often perceived to be insurmountable (Chankova et al, 2009; Likupe, 2013). Incentives to migrate include higher pay rates, better working conditions and the attraction of working in welldeveloped health systems within high-income countries. Such influences are particularly difficult to combat - particularly in the context of the extensive global shortages of HRH. Governments and professional regulatory bodies are then left with little choice but to focus their efforts on factors within their direct control, to reduce the local disincentives that might encourage health professionals to migrate (Ojakaa et al, 2014). Examples cited by young doctors include: a general dissatisfaction with an underresourced service delivery environment; dissatisfaction with pay; and a lack of influence over policy decisions (Yonga et al, 2012).

In a similar vein, nurses complain about poor remuneration, weak healthcare systems and lack of professional opportunities for advancement locally (Muraguri, 2015). They also highlight the ease with which they can obtain visas to work in English-speaking countries (Likupe, 2013). A recent Kenyan-based study indicated that $20 \%$ of healthcare workers intend to leave their job within the next 2 years, discouraged by poor working conditions, non-competitive pay and, importantly, the lack of opportunity for career development in Kenya (Ojakaa et al, 2014).

\section{Considerations to improve the working context in mental health services in Kenya}

\section{Improving working conditions for psychiatrists and mental health nurses}

A key reason for leaving Kenya cited by doctors and nurses is the poor working conditions. There are very high workloads, inadequate resources, a lack of referral options for patients and limited opportunities for personal development and career progression (Chankova et al, 2009; Likupe, 2013). Mitigating these factors requires a holistic, genuine and large-scale approach by government to scale up in-country HRH production and retention. Kenya has made efforts to reduce the outward flow of nurses (Kenya Ministry of Health \& Nursing Council of Kenya, 2012) but despite these initiatives large numbers of nurses are retiring or migrating to other African countries. There is a particular problem in the field of mental health, because of the low numbers choosing this as a medical or nursing career. Concerted efforts should be made to increase the number of health workforce professionals, by developing and increasing mental health specialty training options.

\section{Encouraging mental health as a career choice - providing supportive continuing professional development}

Kiima \& Jenkins (2010) suggested that there are only 26 psychiatrists practising in public services in Kenya, for a population of some 40 million. Only 43 nurses are currently pursuing a specialty career in mental health. In general, working in this field is not viewed as attractive. Providing good quality professional development opportunities is difficult because there are insufficient numbers to support continuing professional development (CPD) and workers are often unable to attend such programmes because of staff shortages. Therefore dual strategies are needed: first, to promote interest in mental health as a career choice; and second, to provide supportive CPD for professionals already working in the field.

\section{Integrating mental health into primary care}

Given the current national shortage of professionals, a key question is how to scale up mental services. Is there an alternative way of providing support to community services with very small numbers of specialty mental health personnel? Kenya's mental health policy is to integrate mental health into primary care (Kiima \& Jenkins, 2010), and to achieve this goal by delegating less complex 


\begin{tabular}{|c|c|c|c|c|c|c|c|c|c|c|c|c|c|c|c|c|c|c|c|c|c|c|c|}
\hline $\begin{array}{l}\overline{\underline{z}} \\
\stackrel{0}{0}\end{array}$ & 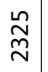 & 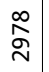 & 후 & $\stackrel{m}{\wedge}$ & $\overline{\tilde{N}}$ & $\bar{\Im}$ & $\stackrel{\vec{m}}{\mathrm{~m}}$ & $\hat{\infty}$ & ถి & - & 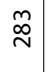 & $m$ & $\tau$ & $r$ & 우 & $r$ & $\mp$ & - & $\mathrm{v}$ & $N$ & in & & $\begin{array}{l}\text { کે } \\
\text { }\end{array}$ \\
\hline$\stackrel{m}{\grave{N}}$ & $\stackrel{\circ}{\circ}$ & $N$ & 1 & $m$ & $\stackrel{n}{m}$ & $m$ & $\lambda$ & 1 & 1 & 1 & $\stackrel{\infty}{\sim}$ & $N$ & 1 & $\tau$ & 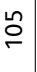 & 1 & 1 & 1 & 1 & 1 & $\sim$ & $\tau$ & ָै \\
\hline ָ̃ & $\mp$ & $\stackrel{\infty}{\circ}$ & $\wedge$ & $r$ & $\stackrel{m}{m}$ & $\checkmark$ & $\checkmark$ & $N$ & 1 & 1 & $\stackrel{\simeq}{0}$ & 1 & 1 & 1 & $\stackrel{\sim}{\sim}$ & 1 & - & 1 & $\sim$ & - & in & 1 & $\stackrel{\stackrel{\sim}{N}}{ }$ \\
\hline $\bar{\Sigma}$ & n & $\stackrel{8}{\circ}$ & v & $\sim$ & $\stackrel{\sim}{N}$ & $m$ & - & $\tau$ & $\tau$ & 1 & 이 & 1 & 1 & 1 & $\checkmark$ & 1 & 1 & 1 & 1 & 1 & 1 & 1 & $\stackrel{\circ}{\circ}$ \\
\hline$\stackrel{\circ}{2}$ & $N$ & $\stackrel{5}{6}$ & 6 & $m$ & $\mathcal{F}$ & $\sim$ & in & - & $\infty$ & 1 & $\stackrel{\infty}{\sim}$ & 1 & 1 & 1 & 1 & $r$ & $\stackrel{\circ}{\circ}$ & $\tau$ & 1 & 1 & 1 & 1 & $\underset{\sim}{\text { D }}$ \\
\hline ঠి & 6 & ஓ् & $\infty$ & $N$ & 우 & $N$ & Ln & n & $\lambda$ & 1 & 우 & $m$ & - & - & 1 & 1 & 1 & 1 & 1 & 1 & 1 & 1 & 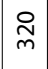 \\
\hline$\stackrel{2}{\infty}$ & $\stackrel{n}{\sim}$ & $\stackrel{\infty}{\sim}$ & $m$ & 1 & $\stackrel{\sim}{m}$ & $\sim$ & - & $N$ & & 1 & $\stackrel{\mathscr{N}}{\sim}$ & 1 & 1 & 1 & 1 & 1 & 1 & 1 & 1 & 1 & 1 & 1 & $\bar{m}$ \\
\hline
\end{tabular}

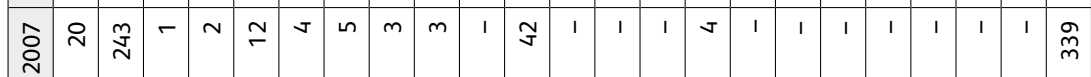

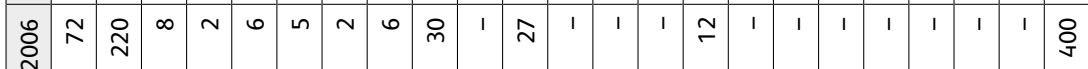

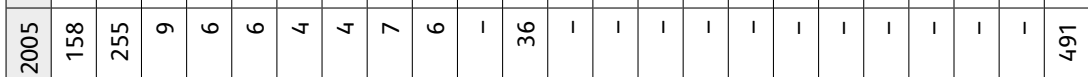

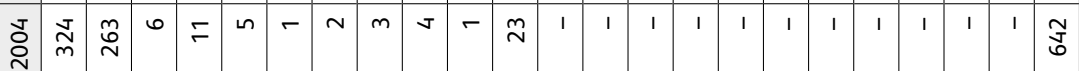

○ั

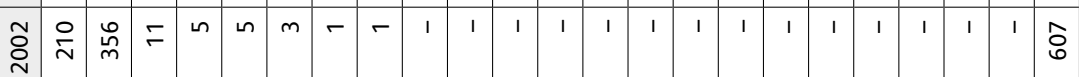

递㑒

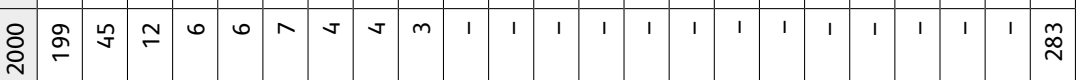

$\frac{m}{\sigma}$

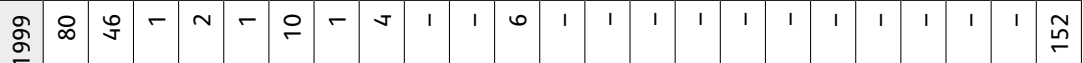

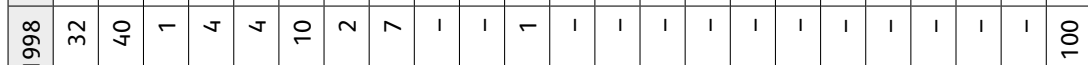

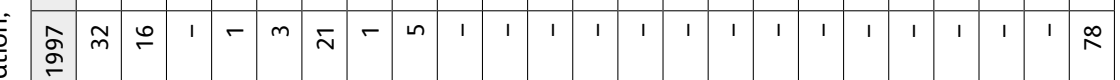

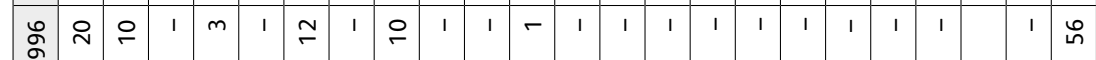

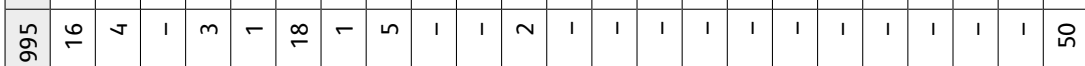

尖

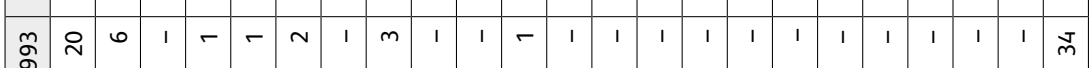

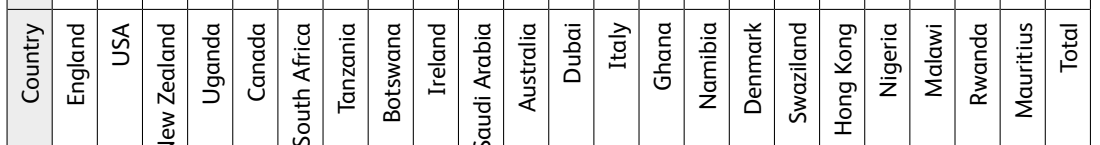

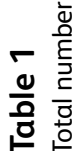


Table 2

Considerations in task shifting: the SUNDAR model

\begin{tabular}{|l|l|}
\hline SUNDAR (meaning 'attractive' in Hindi) & Element of model \\
\hline S & Simplify the message and express concepts in simple terms that lay people can understand \\
\hline UN & Unpack complex healthcare interventions to pieces that can be taught to others \\
\hline D & Deliver close to people and the community \\
\hline A & Use affordable and available human resources to deliver care \\
\hline R & Reallocate effort of specialists to collaborative interprofessional and community engagement \\
\hline
\end{tabular}

Source: Dr Vikram Patel (see https://www.ted.com/speakers/vikram_patel).

functions to less specialised health workers and to lay persons in the community. Psychiatrist Vikram Patel provides useful insights regarding the potential that this offers in 'transforming lives, enhancing communities' (Patel \& Saxena, 2014). Work undertaken by mental health workers and by the lay public can be supported by novel approaches to providing supervision (Patel \& Saxena, 2014).

Table 2 outlines the SUNDAR model for integrating specialist services more closely with community care. It has been trialled in a collaborative project between the Kenya Ministry of Health, the Kenya Medical Training Centre, the Kenya Psychiatric Association and the WHO Collaborating Centre at the Institute of Psychiatry, Psychology and Neuroscience, King's College London. The project developed and implemented a 40-hour CPD programme for front-line primary healthcare workers (nurses and clinical officers). It was rolled out in 2005-2010, through Kenya's national health training system (Kiima \& Jenkins, 2010). The training programme was highly interactive. Role-play focused on the acquisition of basic skills for clinical assessment, diagnosis and management, as well as advocacy and practical skills for the integration of mental health into the generic health system.

Over 2000 primary care staff, district psychiatric nurses, district public health nurses and regional psychiatrists were trained during the programme. Many went on to train their own community health volunteers. A pragmatic cluster randomised controlled trial, in collaboration with the University of Nairobi and Great Lakes University, which was funded by the UK Department for International Development, demonstrated that the clients of trained health workers had better health, social and quality-of-life outcomes than clients of untrained health workers over a 12-week follow-up (Jenkins et al, 2013). We do not know what proportions of these trained staff are still working in primary care in 2016 and further research is needed to track short- and long-term retention - a clear need existing for accurate tracking and monitoring of Kenya's mental health and broader $\mathrm{HRH}$.

\section{Conclusion}

Kenya has made progress in increasing $\mathrm{HRH}$, but they remain well below WHO recommended levels. Progress is hampered by a persistent brain drain of specialist resources - especially in the mental health sector, where the small existing cohort of staff is dwindling. Significant levels of unmet mental health need persist, highlighting the urgency with which government should continue scaling up training, improving health service standards and working conditions while also continuing to roll out the integration of mental health services into primary and community care.

\section{References}

Chankova, S., Muchiri, S. \& Kombe, G. (2009) Health workforce attrition in the public sector in Kenya: a look at the reasons. Human Resources for Health, 7, 58.

Jenkins, R., Kiima, D., Njenga, F., et al (2010) Integration of mental health into primary care in Kenya. World Psychiatry, 9, 118-120.

Jenkins, R., Othieno, C., Okeyo, S., et al (2013) Short structured general mental health in service training programme in Kenya improves patient health and social outcomes but not detection of mental health problems - a pragmatic cluster randomised controlled trial. International Journal of Mental Health Systems, 7, 25.

Kenya Ministry of Health \& Nursing Council of Kenya (2012) Kenya Nursing Workforce Report. The Status of Nursing in Kenya. Kenya Ministry of Health. Available at http://www.health.go.ke/wp content/uploads/2015/09/Kenya \% 20Nursing \% 20Workforce \% 20 Report.pdf (accessed June 2016).

Kiima, D. \& Jenkins, R. (2010) Mental health policy in Kenyaan integrated approach to scaling up equitable care for poor populations. International Journal of Mental Health Systems, 4, 1-8.

Kirigia, J., Akpa Gbary, L. M., Nyoni, J., et al (2006) The cost of health professionals brain drain in Kenya. BMC Health Services Research, 6, 89.

Likupe, G. (2013) The skills and brain drain; what nurses say. Journal of Clinical Nursing, 22, 1372-1381.

Muraguri, M. (2015) Stop brain drain in health sector, Kenya urged. Standard Digital, 7 September.

Odhiambo, G. O. (2013) Academic brain drain: impact and implications for public higher education quality in Kenya. Research in Comparative and International Education, 8, 510-523.

Ojakaa, D., Olango, S. \& Jarvis, J. (2014) Factors affecting motivation and retention of primary health care workers in three disparate regions in Kenya. Human Resources for Health, 12, 1-13.

Otieno, D. (2016) Overwork leading to burn-out among Kenya's nurses. Daily Nation, 15 May.

Oywer, E. (2011) Health Care Models Guiding Mental Health Policy in Kenya. Master of Arts in Health Studies, University of South Africa.

Patel, V. \& Saxena, S. (2014) Transforming lives, enhancing communities - innovations in global mental health. New England Journal of Medicine, 370, 498-501.

Yonga, P. O., Muchiri, H. M. \& Onyino, A. W. (2012) Perceptions of medical brain drain among young doctors in Kenya: a cross-sectional survey. Lancet, 380 (suppl. 2), S22. 